ISSN (e)-2347-176x ISSN (p) 2455-0450

crossrefDOI: https://dx.doi.org/10.18535/jmscr/v7i1.92

\title{
Total Hip Arthroplasthy: Comparison of Lateral and Posterior Approach
}

\author{
Authors
}

\author{
Dr M. Sudhir ${ }^{1}$, Dr M.Chandrashekar ${ }^{2}$ \\ ${ }^{1}$ Assistant Professor, Department of Orthopaedics, Kamineni Academy of Medical Sciences and Research \\ Centre, LB Nagar, Hyderabad \\ Email: drsudhirmoparthi@gmail.com, Mobile no: 889796938 \\ ${ }^{2}$ Senior Resident, Department of Orthopaedics, Government Medical College, Nizamabad \\ Corresponding Author \\ Dr M. Chandrashekar \\ Email: Chandrashekarwgl10@gmail.com, Mobile no: 9491817769
}

\begin{abstract}
The primary goal of total hip arthroplasthy is to improve pain and function. This study was conducted at department of orthopaedics, Kamineni academy of medical sciences and research centre, Hyderabad during January to December 2017 after obtaining permission from hospital ethics committee. This study includes 30 patients which were divided into lateral and posterior approach groups each consist of 15 members. The mean age was 55 years. It includes 17 males and13 females. The duration of surgery in lateral and posterior approaches were 128 and 95 minutes respectively. functional outcome were assessed postoperatively in both the lateral surgical approach group patients and posterior surgical approach group patients using the Harris Hip Score system to evaluate pain and function. The significant improvement was appreciated in the posterior group when compared to lateral group. Trendelenburg test was assessed preoperatively and postoperatively. Although, there is more improvement in the posterior group than the lateral, the $p$ value was not significant. Electrophysiologial study was normal both preoperatively and postoperatively in both groups and hence not significant. The mean Rivermed gait score in posterior approach group were 2.70 and mean Rivermed gait score in lateral approach group were 3.0.There is better improvement of gait in posterior approach group than the lateral approach group. Horizontal and vertical femoral offset ratio were evaluated postoperatively, in both lateral surgical approach group patients and posterior surgical approach group patients using the radiography which was comparable in both groups. Post operative complications like posterior dislocation of hip was observed in one case of posterior approach and Trendelenburg positive score was observed in 4 cases of lateral approach. This study concludes that both were found to be good and any of them can be selected for the total hip arthroplasthy.

Keywords: Total hip arthroplasthy, lateral approach, posterior approach, Harris Hip Score, Trendelenburg test.
\end{abstract}

\section{Introduction}

Total hip arthroplasty (THA) is the hallmark treatment modality for severe arthritis of the hip. Phillip Wiles (1938) performed the first hip arthroplasty. McKee and Farrar28 of Norwich, used a total hip prosthesis with a metal acetabular cup and the Thompson prosthesis of chromium alloy in 1951. In 1966, Ring used a prosthesis, which consisted of a metal acetabular cup, which was screwed into the pelvis ${ }^{[1]}$. 
THA procedure provides excellent patient-reported outcomes and pain mitigation, and is cost-effective when compared with nonoperative care ${ }^{[2,3]}$. The extraordinary success of total hip replacements has led to a progressive increase in the number of replacement surgeries done. There is a difference of opinion among orthopaedic surgeons regardingthe best surgical approach for total hip replacement. Today, the most commonly performed approaches to total hip arthroplasty include the abductor muscle splitting lateral approach and the posterior approach. The lateral approach involves surgical release and repair of the abductor musculature ${ }^{[4]}$. The potential functional implications of violating the abductors is unclear but may negatively impact gait mechanics, including a Trendelenburg gait or a compensatory contralateral pelvic tilt ${ }^{[5]}$. Conversely, the posterior approach involves release and repair of the short external rotators, which can result in changes to rotatory kinetics ${ }^{[6]}$.

Many surgical approaches are used in total hip replacement. Two of the most popular are the posterior and the lateral (Modified Hardinge type) approaches. We studied these since they are the two most commonly performed approaches and both provide adequate exposure for total hip replacement.

\section{Material and Methods}

This study was conducted at department of orthopaedics, Kamineni academy of medical sciences and research centre, Hyderabad during January to December 2017 after obtaining permission from hospital ethics committee. This study includes 30 patients which were divided into lateral and posterior approach groups each consist of 15 members.

For the lateral approach the patient is positioned supine on a sand bag. The modified Hardinge ${ }^{[7]}$ approach was used in all cases. Make a posteriorly directed lazy-J incision centered over the greater trochanter. Divide the fascia lata in line with the skin incision and centered over the greater trochanter. Retract the tensor fasciae latae anteriorly and the gluteus maximus posteriorly exposing the origin of the vastus lateralis and the insertion of the gluteus medius. Incise the tendon of the gluteus medius obliquely across the greater trochanter leaving the posterior half still attached to the trochanter. Carry the incision proximally in line with the fibers of the gluteus medius at the junction of the anterior and middle thirds of the muscle. Distally, carry the incision posteriorly in line with the fibers of the vastus lateralis down to bone along the anterolateral surface of the femur. Elevate the tendinous insertions of the anterior portions of the gluteus minimus and vastus lateralis muscles. Abduction of the thigh then exposes the anterior capsule of the hip joint. The capsule is incised and hip dislocated. During closure, repair the tendon of the gluteus medius with non absorbable braided sutures. In Posterior approach ${ }^{[8]}$, the patient is placed on the unaffected side. Start the incision approximately $10 \mathrm{~cm}$ distal to the poster superior iliac spine and extend it distally and laterally parallel with the fibers of the gluteus maximus to the posterior margin of the greater trochanter. Then direct the incision distally 10 to $13 \mathrm{~cm}$ parallel with the femoral shaft. Expose and divide the deep fascia in line with the skin incision. By blunt dissection separate the fibers of the gluteus maximus; taking care not to disturb the superior gluteal vessels in the proximal part of the exposure. Retract the proximal fibers of the gluteus maximus proximally and expose the greater trochanter. Retract the distal fibers distally and partially divide their insertion into the linea aspera in line with the distal part of the incision. Next, divide the short external rotators at their insertion on the femur and retract the muscles medially. The posterior part of the joint capsule is now well exposed; incise it from distal to proximal along the line of the femoral neck to the rim of the acetabulum. Flex the thigh and knee 90 degrees, internally rotate the thigh, and dislocate the hip posteriorly.

Beginning on the next day morning of surgery, all patients received Low molecular weight heparin and mechanical prophylaxis for thromboembolism in the form of ankle foot pump exercises and calf muscle squeezing. Postoperatively, all patients followed a physical therapy regimen while in 
bed, including isometric knee extension and hip abduction, beginning on the first postoperative day. Ambulation also was permitted on the second postoperative Day after drain removal and radiograph. All Patients treated with uncemented arthroplasties were allowed full weight bearing with crutches, beginning on the second postoperative day. Compliance of patients was excellent in all groups. All these patients were examined 3 months postoperatively for assessment. The functional outcome of hip surgery is measured using Harris Hip Score[9]. It gives a maximum of 100 points. The domains include pain (44 points), Function (47 points), Deformity (4points) and Range of motion(5 points). Score of 90-100 means excellent results, 80-90 being good, 70-79 fair, and below 70 poor. It is assessed before and after surgery to determine improvement. Trendelenburg gait is a study of biomechanics and the gluteus medius and minumus muscles. It allows for functional assessment in a confined space, and is a more valuable clinical sign than many static tests ${ }^{[10]}$. Statistical analysis was done using SPSS version 16.0 for Windows. Data was expressed as frequencies and percentages. The value $>0.5$ considered as significant.

\section{Results}

This study includes 30 cases THA were divided in to two groups. The group L (Lateral approach) 15 cases and group P (Posterior approach) includes 30 cases. Gait analysis was done in all cases pre operatively and 12 weeks after post operatively.

Table 1: Demographic data

\begin{tabular}{|l|c|c|}
\hline & Lateral & Posterior \\
\hline Age & $55.26 \pm 10.23$ & $52.36 \pm 9.52$ \\
\hline Sex(male/female) & $7 / 8$ & $10 / 5$ \\
\hline BMI & $25.6 \pm 4.32$ & $24.64 \pm 3.27$ \\
\hline Duration of surgery & $128 \mathrm{~min}$ & $95 \mathrm{~min}$ \\
\hline
\end{tabular}

Table 2: Etiology

\begin{tabular}{|l|c|c|}
\hline Etiology & Lateral & Posterior \\
\hline Primary osteoarthritis & 10 & 9 \\
\hline Tuberculosis & 2 & 2 \\
\hline Rheumatoid arthritis & 1 & 2 \\
\hline Ankylosing spondylitis & 0 & 1 \\
\hline Avascular necrosis & 1 & 0 \\
\hline Non union neck of femur & 1 & 0 \\
\hline
\end{tabular}

Table 3 clinical outcome

\begin{tabular}{|l|c|c|}
\hline Mean score values & Lateral & Posterior \\
\hline HHS score & & \\
\hline Pre -operative & 42.20 & 34.70 \\
\hline Post-operative & 78.32 & 87.61 \\
\hline Trendelenburg test & & \\
\hline Pre -operative & 5.68 & 5.89 \\
\hline Post-operative & 3.46 & 2.00 \\
\hline Gait score & & \\
\hline Pre -operative & 22.0 & 26.5 \\
\hline Post-operative & 9.00 & 6.72 \\
\hline Pain score & & \\
\hline Pre -operative & 20.34 & 25.87 \\
\hline Post-operative & 16.00 & 14.08 \\
\hline Function score & & \\
\hline Pre -operative & 22.65 & 15.76 \\
\hline Post-operative & 31.98 & 40.43 \\
\hline
\end{tabular}

Table 4 Number patients showing HHS scores

\begin{tabular}{|l|c|c|}
\hline HHS & Lateral & Posterior \\
\hline Excellent & 4 & 6 \\
\hline Good & 8 & 8 \\
\hline Fair & 2 & 1 \\
\hline Poor & 1 & 0 \\
\hline
\end{tabular}

The functional outcome of hip surgery is measured using Harris Hip Score. Preoperative and postoperative Harris Hip Score were obtained to evaluate pain and function. The significant improvement was appreciated in the posterior group when compared to lateral group.

Trendelenburg test was assessed preoperatively and postoperatively. Although, there is more improvement in the posterior group than the lateral, the $\mathrm{p}$ value was not significant.

Electrophysiologial study was normal both preoperatively and postoperatively in both groups and hence not significant. The mean Rivermed gait score in posterior approach group were 2.70 and mean Rivermed gait score in lateral approach grop were 3.0.There is better improvement of gait in posterior approach group than the lateral approach group.

Horizontal and vertical femoral offset ratio were evaluated postoperatively, in both lateral surgical approach group patients and posterior surgical approach group patients using the radiography. The mean Horizontal and vertical femoral offset ratio in posterior approach group were 0.970 and 0.980 respectively and mean Horizontal and 
vertical Femoral offset ratio in lateral approach group were 1.00 and 1.70.Although there is better vertical femoral offset ratio in posterior approach group which is not statistically significant. Post operative complications like posterior dislocation of hip was observed in one case of posterior approach and Trendelenburg positive score was observed in 4 cases of lateral approach.

\section{Discussion}

The primary goal of total hip arthroplasty is to improve pain and function. In our study lateral and posterior approaches were done each 15 of patients.

The advantages of the lateral approach are that it provides adequate exposure of both proximal femur and acetabulum ${ }^{[11]}$ thereby allowing proper acetabular cup positioning and decreased incidence of hip dislocation ${ }^{[12]}$ There is also decreased incidence e of sciatic nerve injury, because the nerve is away from the surgical field and also preserves the posterior joint capsule. However, the disadvantages are that there are increased chances for the superior gluteal nerve ${ }^{[13]}$ and the gluteus medius muscle to get injured. This may result in delayed recovery of strength of the abductor musculature and cause Trendelenburg gait. Learmonth ${ }^{[14]}$ in 1996 described a modified lateral approach to the hip which exploits the functional continuity of gluteus medius and vastus lateralis and their dense crescentic attachment to the greater trochanter. The gluteus medius is not incised or split, but is detached and mobilised with gluteus minimus as one unit. This facilitates reattachment of the glutei and helps to preserve abductor function.

Mulliken et al. ${ }^{[15]}$, in a review of 770 total hip replacements via the lateral approach, found a $10 \%$ incidence of moderate or severe limp at 2 years. Baker and Bitounis ${ }^{[16]}$ found more positive postoperative Trendelenburg tests after the lateral approach than after the posterior one and considered that this weakness was due to detachment of the glutealflap, although they did not quantify abductor strength
The advantages of the posterior approach are that it is rapid, almost bloodless and attended by little shock. The gluteus maximus and tensor fasciae latae, which are so important for stability of the hip, are not weakened and the operation causes no instability ${ }^{[17]}$ Barber et al ${ }^{[18]}$ compared 28 total hip replacement operated on using the posterior approach versus 21 hips using the direct lateral approach. Cemented and uncemented implants were used in both approaches in different proportions. At 2 years follow-up, no dislocations were recorded in either group. A Trendelenburg test score as well as a limp score and an abductor power score were recorded without significant differences between groups. The presence of a postoperative Trendelenburg gait was conducted by many authors these indicate no significant difference between posterior versus direct lateral surgical approach $[15,18,19]$

In posterior surgical approach group one patient had posterior dislocation in the posterior approach group but no dislocations were encountered in the lateral approach group. On analysing the cause for dislocation it was found that dislocation was due to the retroverted acetabular cup (5 degree of retroversion).This complication can be prevented by stabilising the patient in proper lateral position with pubic support, identifying the transverse acetabular ligament ${ }^{[20]}$

\section{Conclusion}

According to our prospective study of the two approaches, were found to be good, that any of them can be selected for the total hip arthroplasthy.

\section{References}

1. Ring PA, Complete replacement arthroplasty of the hip by the ring prosthesis. $\mathrm{J}$ Bone Joint Surg Br 1968;50: 720-31.

2. Learmonth I, Young C, Rorabeck C. The operation of the century: total hip replacement. Lancet. 2007;370:1508-19.

3. Chang R, Pellissier J, Hazen G. A costeffectiveness analysis of total hip 
arthroplasty for osteoarthritis of the hip. JAMA. 1996;275:858-65.

4. Hardinge $\mathrm{K}$. The direct lateral approach to the hip. J Bone Joint Surg Br. 1982;64:179.

5. Pospischill M, Kranzl A, Attwenger B, et al. Minimally invasive compared with traditional transgluteal approach for total hip arthroplasty: a comparative gait analysis. J Bone Joint Surg Am. 2010;92:328-37

6. Rathod P, Orishimo K, Kremenic I, et al. Similar improvement in gait parameters following direct anterior and posterior approach total hip arthroplasty. J Arthroplasty. 2014;29:1261-4.

7. Frndak PA, Mallory TH, Lombardi Jr AV: Translateral surgical approach to the hip. The abductor muscle "split". Clin Orthop 95:135-141, 1993

8. Moore AT. In: American Academy of Orthopaedic Surgeons editor (s). Instructional Course Lectures. Vol. 16, St Louis: CVMosby, 1959.

9. Harris WH. Traumatic arthritis of the hip after dislocation andacetabular fractures: treatment by Mold arthroplasty. An endresult study using a newmethod of result evaluation. J Bone Joint Surg [Am] 1969;51A:737-55.

10. Pai VS :Significance of the Trendelenburg test in total hip arthroplasty. Influence of lateral approaches.J Arthroplasty.1996 Feb;11(2):174-9.

11. Lord S.E, Halligan P.W, Wade D.T: Visual gait analysis:the development of a clinical assessment and scale.Clin Rehabil 1998; $12 ; 107$

12. Hoppenfeld S, DeBoer P, Buckley R. Surgical exposures in orthopaedics: the anatomic approach. Philidelphia, PA: Lippincott Williams and Wilkins;2009

13. Kwon MS, Kuskowski M, Mulhall K, et al. Does surgical approach affect total hip arthroplasty dislocation rates? Clin Orthop Relat Res.2006;447:34
14. Learmonth ID, Allen PE. The Omega Lateral Approach to thehip .J Bone Joint Surg [Br] 1996;78-B:559-61.

15. Muller ME. Total Hip replacement: Planning Technique andComplications In: Surgical Management of Degenerative arthritis of the Lower Limb. Heidelberg: Lea and Febiger; 1975,p. 91

16. Baker AS, Bitounis VC. Abductor function after total hip replacement .An electromyographic and clinical review. J Bone Joint Surg 1989;71- B:47-50.

17. Gore DR, Murray SP, Sepic SB, Gardner GM: Anterolateral compared to posterior approach in total hip arthroplasty: Difference in component positioning, hip strength, and hipmotion. Clin Orthop 165:180-187, 1982

18. Barber TC,Roger DJ,Goodman SB, Schurman DJ. Early outcome of total hip arthroplasty using the direct lateral vs the posterior surgical approach. Orthopedics 1996;19:873-5.

19. Downing ND, Clark DI, Hutchinson JW, Colclough K, Howard PW. Hip abductor strength following total hip arthroplasty Aprospective comparison of the posterior and lateral approach in 100 patients. Acta Orthop Scand 2001;72:215-20.

20. S. Zimmera, W. G. Hawkes, J. I. Hudson et al, "Outcomes of surgical management in patients aged 65 years and older: cemented versus cementless femoral compoments and lateral or anterolateral versus posterior anatomical approach," J. Orthop. Res, vol. 20(2), pp. 182- 191,2002 